\title{
Metachronous Bilateral Testicular Tumours of Differing Histologies
}

\author{
Maj P J Parker
}

MB, FRCS (Ed), RAMC

Surgical Registrar

\section{Queen Elizabeth Military Hospital, Woolwich, London SE184QH}

SUMMARY: Bilateral Testicular tumours are rare. A teratoma followed by a seminoma is one of the most uncommon forms of presentation. A case is described in a 29 year old soldier with a review of the literature and a discussion of the problems associated with diagnosis.

Sgt X presented to this hospital in late 1990 having been casevaced from the Gulf. He had presented there with a four day history of a swelling in the left side of his scrotum. He was otherwise well and specifically denied any pain, trauma, sexually transmitted disease or maldescent as a child.

Examination revealed a fit 29 year old man with a $5 \mathrm{x}$ $4 \mathrm{~cm}$ craggy swelling on his left testis. Ultrasound showed a solid multilobular testis. A diagnosis of testicular cancer was made and after pre-operative estimations of alphafetoprotein (AFP) and beta-subunit of HCG ( $\beta$ HCG) a left radical orchidectomy was performed on 31 Dec 90. Histology showed a Malignant Teratoma Trophoblastic (MTT) with areas of yolk sac differentation. No seminomatous areas were seen. The spermatic cord, epididymis and testicular capsule were free of tumour. Immunochemistry for B-HCG was strongly positive in the numerous areas of trophoblastic differentiation.

Routine staging tests were performed. A CT scan of the abdomen and thorax as well as abdominal ultrasound and high $\mathrm{KV}$ chest $\mathrm{X}$-ray were all normal. His tumour markers which had been elevated (Fig 1) returned to normal in line with their half-lives. This is one of the preconditions for inclusion (as well as normal röentgenography) into the stage I disease category. The half-life of AFP is around five days and that of B-HCG is one day. Chemotherapy was therefore not initiated and he was placed into the teratoma surveillance protocol. Monthly reviews (including serial marker estimations, physical examination and intermittent $\mathrm{CT}$ scanning) were all normal until 30 July 91 .

\begin{tabular}{ccc} 
Tumour Marker & $\begin{array}{c}\text { Alphafetoprotein } \\
\text { (iu/L) }\end{array}$ & beta-HCG (iu/L) \\
\hline Preoperative & 213 & 1452 \\
$9 / 1 / 91$ & 64 & 59 \\
$14 / 1 / 91$ & 28 & 6.6 \\
$21 / 1 / 91$ & 12.3 & 2 \\
$29 / 1 / 91$ & 6.3 & 2.8 \\
$4 / 2 / 91$ & 5.2 & $<2$ \\
$11 / 2 / 91$ & 3.3 & $<2$ \\
\hline
\end{tabular}

Fig 1.
On examination the right testis was noted to be tense and the patient opined that it was larger than before. An ultrasound was immediately carried out which demonstrated some scattered calcification which was thought to be infection; malignancy could not however be ruled out. As this was the patient's sole testicle, intervention was delayed to see if the clinical picture would become any clearer.

At review on 4 Sept 91 there had been no further enlargement and another ultrasound was obtained. This was more confidently reported as showing changes in keeping with malignancy and in retrospect it was felt that the previous ultrasound should have been reported as demonstrating a tumour.

The patient proceeded to right radical orchidectomy on 3 Oct 91. Tumour markers, CT of thorax and abdomen along with abdominal ultrasound and high $\mathrm{KV}$ chest X-ray were normal. Histology demonstrated a pureo seminoma of the right testicle. The bulk of the testicle had been replaced by sheets of cells with central vesica: nuclei. The features were those of a seminoma with no teratomatous elements. The spermatic cord was free of tumour but there were occasional foci of what was thought to be vascular invasion. This was stage I disease and in view of the above it was decided to treat him with four courses of BEP (Bleomycin, Etoposide and cisPlatinum). On $3 \mathrm{Dec} 91$ he had two $200 \mathrm{mcg}$ pellets of testosterone implanted into his abdominal wall. He remains well.

\section{Discussion}

Testicular tumours are the commonest cancers of young men. There are around 600 new cases each year in the UK (1). These may be bilateral in 1.56 to $5 \%$. These bilateral tumours may be synchronous (simultaneous) or metachronous (successive). The histologies may be different or identical. Metachronous seminoma is the commonest bialateral tumour and synchronous seminoma the next commonest (2). A teratoma followed by a seminoma is probably the rarest type of bilateral tumour.

The first reported case of cancer of both testicles was in 1805 (3). A 33 year old seaman complained of unequal, enlarged, hard testicles. Interestingly superadded infection and scurvy led to the destruction of 
both testicles. After treatment with "as many limes as he could eat" and washing the area with dilute lime juice he made a full recovery and was performing his duties as a sailor two months later.

In a review in 1978, Aristizabal quoted a $1.56 \%$ incidence (76/4864 cases) (2). Of the cases that he reviewed $50 \%$ of the second primaries were diagnosed within 5 years. Bach treated 367 patients with testicular cancer from 1966 to 1980 (4). The condition was bilateral in 18 , a rate of $4.6 \%$. However of these only one was a teratoma followed by a seminoma and then with a 17 year interval.

Dieckmann in a series of 181 patients in 1985 found 9 cases of bilateral involvement $(5 \%)(5)$. Synchronous seminoma was commonest $(3 / 9)$. There were no teratomas followed by seminoma but there was one teratoma/seminoma mixed followed by a pure seminoma some 4 years later. He pointed out that one of the main difficulties in diagnosis of a second tumour was the patients fear of castration and therefore reluctance of presentation. He recommended; detailed counselling (especially in the high risk cryptorchid group), periodic self examination, long follow-up and repeated sonography.

\section{The Rôle of Biopsy?}

In a series of 500 patients in 1985 a Copenhagen study group performed biopsy of the contralateral testis in patients with unilateral testicular (germ-cell) cancer (6). Carcinoma in situ was found in $27 / 500$ patients $(5.4 \%)$. Intensive chemotherapy for their initial cancer was given in $8 / 27$ and none of these had any further disease. Of the remaining 19 (biopsy positive $\mathrm{Ca}$-in situ) 7 developed cancer in that remaining testis. Four were seminomas, 2 were early invasive growths and 1 was a seminoma with embryonal carcinoma. None of the 473 patients without carcinoma in situ developed cancer in that testis. This procedure is now performed on $80 \%$ of all new patients with unilateral testicular cancer in Eastern Denmark. The biopsy requires a $4 \mathrm{~mm}$ cut at the time of 3 orchidectomy and they point out that no serious $\stackrel{\varnothing}{\propto}$ complications arose.

\section{Conclusion}

Bilateral testicular tumours are uncommon. A $\vec{\Rightarrow}$ teratoma followed by a seminoma represents one of the most uncommon forms of presentation. Routine biopsy may become the norm but as ultrasound increases in sensitivity so it may have a part to play in the diagnosis of smaller and smaller cancers. The prognosis of such germ cell tumours is considered to be good and relates $\%$ primarily to the stage of the tumour. This case serves to $\vec{\circ}$ increase the awareness and highlight the problems of such a diagnosis.

\section{Acknowledgement}

I would like to thank Lt Col R Brookstein for allowing me to present this case.

\section{REFERENCES}

1. McLatchie G. Oxford Handbook of Clinical Surgery. OUP 1990; 576.

2. Aristizabal S, Davis J R, Miller R. Bilatera度 primary germ cell tumours. Cancer $1978 ; 42: 591-7 . \overrightarrow{\mathrm{D}}$

3. LivingSTONE J. A case of cancer of both testiclo which terminated favourably by the supervention o\& scurvy. Med Surg J (Edinburgh) 1805; 1: 163-5.

4. BaCH D, Weissbach L, Hartlapp J. Bilaterah Testicular Tumour. J Urol 1983; 129: 989-991.

5. Dieckmann K-P, Boeckmann W, Brosig W. Bilat eral Testicular Germ Cell Tumour. Cancer 1986; 52 1254-8.

6. Von der MAsSe H, Rorth M, Walbom-Jorgensen $\mathrm{S}$, et al. Carcinoma in situ of contralateral testis in patients with testicular germ cell cancer: Study of 27 cases in 500 patients. $\mathrm{Br}$ Med $J$ 1986; 293: 1398 1401. 